\title{
THE PRECESSIONAL CONSTANT, PARAMETERS \\ OF SOLAR MOTION \\ AND GALACTIC ROTATION IN THE FK 4 SYSTEM
}

\author{
By N. A. BOSHNIAKOVICH.
}

RÉsumé. - Ce travail donne les résultats d'une investigation portant sur les changements de la constante de la précession, des paramètres du mouvement du Soleil et de la rotation galactique provenant du passage du système FK 3 au système FK 4 .

Abstract. - In this paper, an investigation is made of the changes in the constant of precession, parameters of solar motion and of galactic rotation, caused by the transition from the FK 3 to the FK 4 system.

Zusammenfassung. - In dieser Arbeit werden die Änderungen untersucht, welchen die Präzessionskonstante sowie die Parameter der Sonnenbewegung und der galaktischen Rotation durch den Übergang vom System des FK 3 auf das System des FK 4 erleiden.

Резюме. - В этой работе изложены результаты исследования изменений постоянной прецессии, параметров движения Солнца, и характеристик галактического вращения, происходящих от замены системы FK3 системой FK 4 .

In this investigation, the differences, $\Delta \mu_{x}$ and $\Delta \mu_{i}$ of proper motions of 1534 stars of FK 3 taken as FK 4 minus FK 3 were used.

These differences were averaged for each of 432 trapezia, uniformly distributed all over the sky, with sides of $\mathrm{I}^{\circ}$ in declination and $\mathrm{I} \mathrm{h}$ in right ascension. It was assumed that the arithmetical mean of star co-ordinates for each trapezium coincides with its center.

Ten trapezia contained no stars at all. The mean proper motions were estimated for them by interpolating the values obtained for the neighbouring trapezia.

The equations (I) are derived from those given in Schilt's paper [1], the unknown quantities being substituted by their corrections and the 
proper motions in the free terms substituted by the differences of proper motions.

$$
\left\{\begin{array}{c}
\Delta \mathrm{X} \sin \alpha-\Delta \mathrm{Y} \cos \alpha+2 \Delta \mathrm{A} \cos \delta \cos 2 \alpha+2 \Delta \mathrm{B} \cos \delta \sin 2 \alpha \\
+\Delta(\mathrm{C}+0.15 \mathrm{Q}+\Delta n) \sin \delta \sin \alpha+\Delta(\mathrm{D}+0.86 \mathrm{Q}) \sin \delta \cos \alpha \\
+\Delta(0.46 \mathrm{Q}+\Delta k) \cos \delta=\Delta \mu^{s} \cos \delta \\
\Delta \mathrm{X} \sin \delta \cos \alpha+\Delta \mathrm{Y} \sin \delta \sin \alpha-\Delta Z \cos \delta-\Delta \mathrm{A} \sin 2 \delta \sin 2 \alpha \\
+\Delta \mathrm{B} \sin 2 \delta \cos 2 \alpha-\Delta \mathrm{C} \cos 2 \delta \cos \alpha+\Delta \mathrm{D} \cos 2 \delta \sin \alpha+\Delta \mathrm{E} \sin 2 \delta \\
-0.86 \Delta \mathrm{Q} \sin \alpha+\Delta(0 . \mathrm{I} \delta \mathrm{Q}+\Delta n) \cos \gamma=\Delta \mu^{\prime},
\end{array}\right.
$$

where

$$
\left\{\begin{array}{l}
\Delta \mathrm{A}=+0.104 \Delta(\mathrm{P} \sin 2 l)-0.220 \Delta(\mathrm{P} \cos 2 l) \\
\Delta \mathrm{B}=-0.287 \Delta(\mathrm{P} \sin 2 l)-0.080 \Delta(\mathrm{P} \cos 2 l), \\
\Delta \mathrm{C}=-0.409 \Delta(\mathrm{P} \sin 2 l)-0.154 \Delta(\mathrm{P} \cos 2 l) \\
\Delta \mathrm{D}=+0.072 \Delta(\mathrm{P} \sin 2 l)-0.870 \Delta(\mathrm{P} \cos 2 l), \\
\Delta \mathrm{E}=+0.585 \Delta(\mathrm{P} \sin 2 l) .
\end{array}\right.
$$

Here $\Delta \mathrm{X}, \Delta \mathrm{Y}, \Delta \mathrm{Z}$ are the corrections to the components of the solar motion :

$$
\begin{aligned}
& \mathrm{X}=\left(\begin{array}{c}
\bar{h} \\
\rho
\end{array}\right) \cos \mathrm{D} \cos \Lambda, \\
& \mathrm{Y}=\left(\frac{h}{\rho}\right) \cos \mathrm{D} \sin \mathrm{A}, \\
& \mathrm{Z}=\left(\begin{array}{c}
\bar{h} \\
\rho
\end{array}\right) \sin \mathrm{D},
\end{aligned}
$$

where $\left(\frac{h}{\rho}\right)$ is the mean secular parallax (in seconds of arc); $A$ and D are the equatorial co-ordinates of the apex; $\Delta \mathrm{A}, \Delta \mathrm{B}, \Delta \mathrm{C}, \Delta \mathrm{D}$ and $\Delta \mathrm{E}$ can be expressed in terms of $\Delta\left(\mathrm{P} \sin _{2} l\right)$ and $\Delta(\mathrm{P} \cos 2 l)$ using equations! ( $\left.1^{\prime}\right)$ where $l$ is the longitude of the galactic center and $\mathrm{P}$ is the correction of Oort's constant $A$, divided by 4.74 , that is $P=\frac{A}{4.74}$.

Similarly $\Delta Q$ in the equations ( $\mathrm{r}$ ) is the correction to Oort's constant $B$ divided by 4.74 , that is $Q=\frac{B}{4.74}$.

$\Delta(\Delta n)$ is the variation of the precession correction in declination $\Delta n$; $\Delta(\Delta k)$, an analogous variation of $\Delta k$ which is the precessional correction in right ascension, including the corrections of planetary precession and motion of equinox.

The terms $\Delta(\mathrm{P} \sin 2 l)$ and $\Delta(\mathrm{P} \cos 2 l)$ in the above relations can be represented as

$$
\begin{aligned}
& \Delta(\mathrm{P} \sin 2 l)=\left(\mathrm{P}_{0}+\Delta \mathrm{P}\right) \sin 2\left(l_{0}+\Delta l\right)-\mathrm{P}_{0} \sin 2 l_{0}, \\
& \Delta(\mathrm{P} \cos 2 l)=\left(\mathrm{P}_{0}+\Delta \mathrm{P}\right) \cos 2\left(l_{0}+\Delta l\right)-\mathrm{P}_{0} \cos 2 l_{0},
\end{aligned}
$$


which allow to derive the $\Delta \mathrm{P}$ and $\Delta l$ corrections in the sense of the difference FK $4-$ FK 3.

The determination of $l$ from proper motions being uncertain, we assumed thal $\Delta l=o$ and the standard value of the galactic center longitude $\left(3_{2} 5^{\circ}\right)$ was taken for $l_{0}$. In this case it is possible to determine $\Delta \mathrm{P}$ directly from equations (I) substituting the expression $\Delta \mathrm{A}, \Delta \mathrm{B}, \Delta \mathrm{C}, \Delta \mathrm{D}$ and $\Delta \mathrm{E}$ from $\left(\mathrm{I}^{\prime}\right)$.

Equal weights were given to all the equations of the form (I). The solutions were made independently for $\Delta \mu_{\alpha}$ and $\Delta \mu_{i}$.

The first two columns of table I represent the results of calculation from the differences of proper motions separately in right ascension and declination. The third column gives the mean weighted values from the previous two columns. The forth column represents the corrections for the precessional constant and the galactic rotation parameters determined by Morgan and Oort [2] as a result of the transition from the $\mathrm{N} 30$ to the FK 3 system. These corrections were used for obtaining corresponding differences between the $\mathrm{N} 30$ and FK 4 systems given in the last column of table $\mathrm{I}$. All the values in this table are expressed in seconds of arc per century.

As it is seen from the table, the values $\Delta(\Delta n), \Delta \mathrm{P}$ and $\Delta \mathrm{Q}$ determined from proper motions in declination are more precise than those in right ascension. The weights of $\Delta \mathrm{X}$ and $\Delta \mathrm{Y}$ as determined from the equations in $\alpha$ are greater than those determined from the equations in $\delta$, but as the probable error per unit of weight for $\Delta \mu_{\alpha}$ is larger than that for $\Delta \mu_{i,}$, the mean square errors of the unknowns $\Delta \mathrm{X}$ and $\Delta \mathrm{Y}$ appear to be equal in both cases.

TABLE I.

\begin{tabular}{|c|c|c|c|c|c|}
\hline & $\begin{array}{l}\text { FK } 4-F K 3 \\
\text { in } \Delta u_{\alpha} . \\
\end{array}$ & $\begin{array}{l}\mathrm{FK} 4-\mathrm{FK} 3 \\
\text { in } \Delta \ell_{\delta} .\end{array}$ & $\begin{array}{c}\text { FK } 4-F K 3 \\
\text { mean weighted. }\end{array}$ & $\begin{array}{c}\text { N } 30-\mathrm{FK} 3 \\
\text { (Morgan } \\
\text { and Oorl). }\end{array}$ & N $30-\mathrm{FK} 4$ \\
\hline$\Delta X \ldots \ldots$ & $\begin{array}{c}\prime \prime \\
-0.02-0.0 \%\end{array}$ & $\begin{array}{c}\prime \prime \prime \\
+0.03=0.02\end{array}$ & $0^{\prime \prime} 00 \pm 0.0 \mathrm{I}$ & - & $\begin{array}{l}\prime \prime \\
-\end{array}$ \\
\hline$\Delta \mathrm{Y} \ldots \ldots$ & $-0.10 \pm 0.02$ & $+0.08 \pm 0.02$ & $-0.0 \mathrm{I} \pm 0.0 \mathrm{I}$ & - & - \\
\hline$\Delta \mathrm{Z} \ldots \ldots$ & - & $+0.07 \pm 0.0 \mathrm{I}$ & $+0.07 \pm 0.0 \mathrm{I}$ & - & - \\
\hline$\Delta(\Delta n) \ldots$ & $+0.12 \pm 0.03$ & $-0.09 \pm 0.0 \mathrm{I}$ & $-0.07 \pm 0.01$ & $+0.0 \mathrm{I}$ & +0.08 \\
\hline$\Delta(\Delta k) \ldots$ & $+0.13 \pm 0.02$ & - & $+0.13 \pm 0.02$ & +0.18 & +0.05 \\
\hline$\Delta P \ldots \ldots$ & $-0.12 \pm 0.05$ & $-0.12 \pm 0.02$ & $-0.12 \pm 0.02$ & +0.05 & +0.17 \\
\hline$\Delta Q \ldots \ldots$ & $-0.06 \pm 0.04$ & $-0.01 \pm 0.01$ & $-0.0 \mathrm{I} \pm 0.0 \mathrm{I}$ & +0.05 & $+o .06$ \\
\hline
\end{tabular}

Using the solar motion parameters : $\mathrm{X}=+\mathrm{o}^{\prime \prime} .07, \mathrm{Y}=-\mathrm{0}^{\prime \prime} .98$, $\mathrm{Z}=+\mathrm{o}^{\prime \prime} .56$ détermined by Vyssotsky and Williams [3] in the FK 3 system from proper motions of 69 ooo stars and also our corrections $\Delta \mathrm{X}, \Delta \mathrm{Y}, \Delta \mathrm{Z}$ - we obtain the right ascension of the apex in the FK 4 system equal to $274^{\circ} . \mathrm{r}$, i. e. the same as that in the FK 3 system. The declination of the apex in the FK 4 system $\left(+32^{\circ} \cdot 4\right)$ 
deviates from the standard value $\left(+30^{\circ}\right)$ more than in the FK 3 system $\left(+29^{\circ} \cdot 7\right)$.

In the transition from the FK 3 to the FK 4 system, the correction of the annual lunisolar precession $\Delta\left(\Delta \mathrm{P}_{1}\right)$ is $-\mathrm{o}^{\prime \prime} . \mathrm{I} 8$ and the correction of equinox $\Delta(\Delta \mathrm{E})$ is $-\mathrm{o}^{\prime \prime} .3 \mathrm{I}$.

The agreement of the precessional correction $\Delta n$ between the FK 3 and FK 4 systems is not so good as between the FK 3 and N 30 systems; however the difference of $\Delta k$ for the FK 4 and N 30 systems is smaller than for the FK 3 and N 30 systems.

In the paper of J. E. Gordon [4] are given the values of $\Delta P_{1}$ and $\Delta E$ which were obtained by 13 authors in different systems of proper motions (Auwers', PGC, GC and FK 3) taking into account the galactic rotation. The mean weighted values taken from this paper are

$$
\begin{aligned}
& \Delta P_{1}=+1^{\prime \prime} .09 \pm o^{\prime \prime} .03 \\
& \Delta E=+1^{\prime \prime} .24 \pm 0^{\prime \prime} .03 .
\end{aligned}
$$

The mean weighted values of four determinations ([3], [4], [6], [7]) in the FK 3 system are

$$
\begin{aligned}
& \Delta P_{1}=+\mathrm{I}^{\prime \prime} .23 \pm \mathrm{o}^{\prime \prime} .09 \\
& \Delta \mathrm{E}=+\mathrm{I}^{\prime \prime} .43 \pm \mathrm{o}^{\prime \prime} . \mathrm{I} \mathrm{I}
\end{aligned}
$$

In order to obtain these values in the FK 4 system our corrections $\Delta\left(\Delta \mathrm{P}_{1}\right)$ and $\Delta(\Delta \mathrm{E})$ were added to the above results which gives

$$
\begin{aligned}
& \Delta P_{1}=+I^{\prime \prime} .05 \\
& \Delta E=+I^{\prime \prime} .1 \%
\end{aligned}
$$

Our values are in good agreement with the results of the 13 authors and agree with the mean values deduced from all the modern determinations $\left(\Delta \mathrm{P}_{1}=\mathrm{I}^{\prime \prime}\right.$.oo, $\left.\Delta \mathrm{E}=\mathrm{I}^{\prime \prime} . \mathrm{I} 3\right)$ better than the FK 3 system [5].

Using the $\Delta \mathrm{P}_{1}$ and $\Delta \mathrm{E}$ corrections we get in the FK 4 system the annual lunisolar precessional constant $\mathrm{P}_{1}=5 \mathrm{o}^{\prime \prime} .3838$, the precession in right ascension $m=46^{\prime \prime} .1087$ and in declination $n=20^{\prime \prime} .0468$ (for 1950.0 ).

We have not determined $\Delta l$; the difference of the value of $\mathrm{P}$ in the systems FK 4 and FK 3 is considerable. Besides its value in the FK 4 system deviates from the standard value more than in the FK 3 system.

Using the $P$ and $Q$ values determined by Vyssotsky and Williams [3] in the FK 3 system and our $\Delta \mathrm{P}$ and $\Delta \mathrm{Q}$ corrections for reducing them to the FK 4 system we estimated the angular velocity of galactic rotation in the vicinity of the Sun $\omega_{0}=0^{\prime \prime} .0049$ per year, which gives $264 \times 10^{6}$ years for the period of galactic rotation, i. e. 74 million years longer than the standard period.

It seems that the FK 4 system has no advantages in the determination of parameters of galactic rotation. 


\section{REFERENCES.}

[1] J. Schilt, Astron. J., Vol. 39, 1928, p. 17.

[2] H. R. Morgan and J. H. Oort, B. A. N., vol. 11, No. 431, 195 r.

[3] A. N. Vyssotsky and Emma F. R. Williams, Publications of the Leander Mc Cormick Observatory of the University of Virginia, vol. 10, 1948.

[4] J. E. Gordón, Bull. of the Pulkovo Obs., vol. 19, No. 148, $195 \mathrm{r}$.

[5] K. A. Kulikov, Spherical Astronomy, 1961 (in russian).

[6] J. H. Oort, B. A. N., vol. 9, 1943, p. 424.

[7] W. Gliese, $A$. ., vol. 270, 1940, p. 127. 